\title{
Role of hydroxyl benzoic acid foliar spray on amelioration of lead tolerance on Triticum aestivum $\mathbf{L}$.
}

\author{
Naveen Dilawar ${ }^{1}$, Fayaz Asad $^{1 *}$, Sabrina Shahid ${ }^{1}$, Samiullah $^{2}$ and \\ Wisal $^{1}$ \\ 1. Department of Botany, Bacha Khan University Charsadda, KP-Pakistan \\ 2. Departement of Botany, University of Peshawar, KP-Pakistan \\ *Corresponding author's email: fayaz.asad79@yahoo.com
}

Citation

Naveen Dilawar, Fayaz Asad, Sabrina Shahid, Samiullah and Wisal. Role of hydroxyl benzoic acid foliar spray on amelioration of lead tolerance on Triticum aestivum L. Pure and Applied Biology. Vol. 10, Issue 3, pp861-871. http://dx.doi.org/10.19045/bspab.2021.100088

\begin{tabular}{|c|c|c|c|}
\hline Received: 01/08/2020 & Revised: $17 / 11 / 2020$ & Accepted: $27 / 11 / 2020$ & Online First: $19 / 12 / 2020$ \\
\hline
\end{tabular}

\section{Abstract}

Heavy metal pollution of water and soil has become a global issue, which extensively effect the major cereal crops and human health in the world. Current study aimed to conduct the role of exogenously applied Hydroxyl Benzoic Acid (HBA) foliar spray on agronomic and physicochemical parameters of two varieties of Triticum aestivum L. i.e. Jhanbaz and Galaxy 2013 under the lead (heavy metal) stress. Leaves of the above plants were treated (after 7, 14, 21 days) with distilled water (control), $2 \mathrm{ppm} \mathrm{Pb}^{2+}(\mathrm{T} 1), 2 \mathrm{ppm} \mathrm{Pb}^{2+}+\mathrm{HBA}(\mathrm{T} 2), 4 \mathrm{ppm} \mathrm{Pb}^{2+}$ (T3), and $2 \mathrm{ppm} \mathrm{Pb}^{2+}+\mathrm{HBA}$ (T4) and response of plants was observed at first, second and third week of the germination. Results of the lead $\left(\mathrm{Pb}^{2+}\right)$ treatment of $4 \mathrm{ppm}$ and $2 \mathrm{ppm}$ showed high adverse effect on physiochemical and growth performance. Whereas HBA foliar spray revealed better performance by improving seedling vigorous index, agronomic parameters and percent field capacity under application of lead at $4 \mathrm{ppm}$ and $2 \mathrm{ppm}$. This indicated that the toxic effects generated by heavy metal stress were relatively overcome by the application of HBA. However, results exhibited the better growth and physicochemical performance were recorded in Jhanbaz as compared to Galaxy 2013 and recommended variety under induced lead stress (lead).

Keywords: Growth performance; Heavy metal; HBA; Lead; Triticum aestivum L.

\section{Introduction}

Heavy metal pollution of water and soil supplies has become a major problem in the modern world. Due to a direct interaction between these sources and the food chain, the excessive concentration of heavy metals is a serious threat to human life [1]. More heavy metal presentation to ground water through polluted soil plays a vital role in health and environmental aspects. $\mathrm{Pb}^{2+}$ is one of the most toxic heavy metals without biological function, which is quickly absorbed by plants and it is toxic to living organisms even at low concentrations [2].
Inevitably, the use of industrial wastewater for agricultural land irrigation has skyrocketed due to water shortage crises and fertility benefits. Lead $\left(\mathrm{Pb}^{2+}\right)$ is a heavy metal of anthropogenic origin [3]. $\mathrm{Pb}^{2+}$ is a pollutant that accumulates in soils, sediments and water and is extremely persistent in the environment [4]. $\mathrm{Pb}^{2+}$ has no biological function and is toxic to living organisms, even at low concentrations. Although $\mathrm{Pb}^{2+}$ is not an essential element, some plant species multiply in an area contaminated with $\mathrm{Pb}^{2+}$ and accumulate it 
in different parts. The roots are the first organ in contact with various components of the rhizosphere [5]. Lead is absorbed by the plants through roots and caused disturbance of ions with in plants [6]. It has been speculated that lead toxic drugs may cause physiological and biochemical changes in the Oryza sativa L. [7]. Lead is not essential for a relatively high reactions of plant cells but it will remove this metal if it is present in their environment, especially in rural area where it is polluted by automobiles exhausts and in farms, contaminated with fertilizers containing heavy metals as impurities [8]. Plants take $\mathrm{Pb}^{2+}$ from the solution in the soil at the roots, and then the largest amount of $\mathrm{Pb}^{2+}$ accumulates in the roots in insoluble form [9]. Accumulation of lead in plants increases with an increase in plant lead levels. Lead can cause a wide range of physical and biochemical dysfunctions in seed germination, plant growth, water conditions and nitrate uptake [10-12].

Lead is one of the most widely used heavy metals and is highly toxic to plants [13]. Throughout the plant, $\mathrm{Pb}^{2+}$ can affect photosynthesis at stoma levels, mesophyll cells, pigment content, and light and dark reactions. Heavy metal pollution of soil and water is a global environmental problem [14]. The objective of this study is to conduct the role of exogenously applied Hydroxyl Benzoic Acid (HBA) foliar spray on agronomic, and physicochemical parameters two varieties of Triticum aestivum L. such as Jhanbaz and Galaxy 2013 under the induced stress of heavy metal (lead).

\section{Materials and Methods}

Peshawar Industrial City Peshawar is a major producer of industrial wastewater in KPK Province. Due to their significant wastewater production, local farmers can use these alternative water resources for irrigation. Three samples of wastewater were taken from an industrial area of Peshawar city. The average concentration of $\mathrm{Pb}^{2+}$ in industrial wastewater was determined by a nuclear absorption spectrophotometer (AAS) and ranged from $2 \mathrm{ppm}$ to $4 \mathrm{ppm}$. To perform this measurement, a lab specialist pumped 100 $\mathrm{ml}$ of dirty water directly into the laboratory [15]. However, the presence of metallurgical fluids in wastewater prevents plants from growing due to its complex biocides and chemicals [16]. Treating mineral fluids was not reasonable or costeffective, so the wastewater was prepared with the infamous $\mathrm{Pb}^{2+}$ solution $(100 \mathrm{mg} /$ 1) developed by Merck Millipour of Germany.

Two different concentrations of solution were prepared, $4 \mathrm{ppm}$ and $2 \mathrm{ppm}$, medium and strong wastewater was used in this study, respectively. The experiment was conducted during the 2015 wheat growing season at the Department of Botany, Bacha Khan University, Charsadda (latitude, 348 b43.080"N, longitude, 7143'50.880"E) and altitude $282 \mathrm{~m}$. Selected Local Blend Jhanbaz and Galaxy 2013 Triticum aestivum L. from Nowshera Cereal Crops Research Institute (CCRI). The seeds were sterilized in a solution of $10 \mathrm{ml}$ of Clorox and $200 \mathrm{ml}$ of water for 3 minutes and then washed with $50 \%$ ethanol for 3 minutes. After that, the seeds were rinsed with distilled water and planted in plastic pots (14 $\mathrm{cm}$ bottom inside diameter, $18.5 \mathrm{~cm}$ top inside diameter, $15.6 \mathrm{~cm}$ height and $0.5 \mathrm{~cm}$ depth). 'Thick) filled with air-dried soil and sand (3: 1) in triplicate pots. They were protected from the rain and 3 pots were submitted to each treatment. The total number of pots was 30 . Plants were watered as needed. Sampling was performed 15 days after the start of treatment with heavy metals. For each treatment, 3 repetitions were taken. After the agronomic study, the samples were dried at room temperature for analysis of the heavy metal $\mathrm{Pb}^{2+}$. (20) Grams of soil of a uniform depth were taken 6 inches from the surfaces of the pots. Dry weight was determined after drying the soil in an oven for 72 hours at $70{ }^{\circ} \mathrm{C}$ until constant weight.

\section{Soil moisture content}

The \%age moisture content of soil is 
calculated by following formula:

$$
\% \text { age moisture content }=\frac{\text { Soil Fresh weight }- \text { Soil Dry weight x100 }}{\text { Soil Fresh weight }}
$$

Field capacity of rhizospheric soil

The field capacity of rhizospheric soil was calculated following the method:

$$
\text { Field Capacity }(\%)=\frac{\text { Wet soil weight }(\mathrm{g})-\text { Dry soil weight }(\mathrm{g}) \times 100}{\text { Dry soil weight }(\mathrm{g})}
$$

Analysis of heavy metal lead for Rhizospheric soil and plant powder

Distilled water of $1 \mathrm{~mL}$ and $9 \mathrm{~mL}$ of rhizospheric clay extracts was taken into a test tube and lead was analyzed on an atomic absorption spectrophotometer. Micronutrients, micronutrients and heavy metals rhizome soil were measured by the formula:

Nutrients $(\mathrm{ppm})=($ Extract in ppm - blank $) \times \frac{\mathrm{A}}{\mathrm{W}} \times$ dilution factor

Whereas

$\mathrm{A}=$ Total extract volume $(\mathrm{ml})$

$\mathrm{W}=$ Rhizospheric soil dry weight

\section{Procedure}

Take the oven dried sample $(0.25 \mathrm{~g})$ in a 50 $\mathrm{ml}$ flask and add $6.5 \mathrm{ml}$ of mixed acid solution, i.e. nitric acid, sulfuric acid, per chloric acid (5: 1: 0.1 ) and boil on a hot plate with extractor hood.

Then a few drops of contaminated water were added and allowed to cool. The

Plant Cation of Nutrient $=($ Extract in $\mathrm{ppm}-$ blank $) \times \frac{\mathrm{A}}{\mathrm{W}} \times$ dilution factor

Whereas

$\mathrm{A}=$ Total volume of extract $(\mathrm{mL})$

$\mathrm{W}=$ Dry Plant Weight

\section{Results and Discussion}

\section{Germination percentage}

When applied $\mathrm{Pb}^{+}$stress Triticum aestivum L. showed reduction in germination but under HBA showed promotion. The maximum germination has been indicated after 7 day(d) and $14 d$ treatment in T3 (V1) and T4 (V2), followed by $\mathrm{T} 4$ (V1) and T3 (V2), while the minimum was found in $\mathrm{T} 1$ (V1) and T5 (V2) while day after of 21 treatments the maximum germination has been found in digested samples were then transferred to a $100 \mathrm{ml}$ volumetric flask and the volume was increased to $100 \mathrm{ml}$ by adding contaminated water. The extract was then filtered through whatsman \# 42 filter paper and stored in plastic bottles labeled filtrate. The concentration of these elements throughout the sample was determined by the Shamadzo AA-670 nuclear absorption spectrophotometer.

$$
\text { W }
$$

T2 (V1) $5.618 \%$ and T4 (V2) with $16 \%$ (Table 1) while the lowest has been reported in T1 (V1) and T5 (V2) our result is also linked with $[17,18]$. Who demonstrated that this metal exerts plant growth, seed germination, shoot growth, root growth, evaporation, chlorophyll production, laminar organization in the cytoplasm and cell division. Sprouts are sensitive to environmental influences in the germination and germination stages [19]. Toxicity of Lead significantly affects the processes of biological in various plants like in maize, barley, wheat, Citrullus, cauliflower and in vegetables. lead 
decreases the seedling growth, shoot length, root length; number of leaves [20].

\section{Shoot and root length}

Heavy metal stress directly affects the plant shoot and root length, the current study indicated that the maximum shoot length was documented in T2 (V1) and T1 (V2) whereas the lowest has been found in $\mathrm{T} 1$ (V1) and T5 (V2). After 14d treatment the maximum shoot length has been indicated in T5 (V1) with $28.6 \mathrm{~cm}$ and T2 (V2), while the minimum has been found in T4 (V1) and T5 (V2). The maximum shoot length after 21d treatment was noted in T3 (V1) and $\mathrm{T} 1$ (V2), whereas the lowest has been reported in T4 (V1) and T2 (V2) (Table 2). While after $7 \mathrm{~d}$ treatment the maximum root length has been found in $\mathrm{T} 1$ (V1, V2) followed by T3 (V1, V2), while the lowest has been noted in T5 (V1, V2). After 14d treatment the maximum root length has been reported in T2 (V1) with $17.25 \mathrm{~cm}$ and T4 (V2) with $11.05 \mathrm{~cm}$, whereas the lowest has been indicated in T5 (V1) and T3 (V2). The maximum root length has been found after 21d treatment in T3 (V1) and T4 (V2), while the lowest has been noted in T1 (V1) and T5 (V2).

Soils contaminated with $\mathrm{Pb}^{2+}$ cause sharp decreases in crop productivity there by poisoning a serious problem for agriculture (21) (Table 3). Similarly, result was also found that Retarded or no root and shoot formation was observed in the Triticum aestivum L. plant when expose to higher concentration of $\mathrm{Cr}$ [21]. Enlarge in heavy metals uptake reduces growth of plant and development for the reason that they start interacting with the micronutrient and limits their availability to the plant. Lead adversely affects plant growth which depends upon its concentration and plant species. Reduction in plant tallness due to $\mathrm{Pb}^{2+}$ is reported in many plants, $11 \%, 22 \%$ and $41 \%$ decrease in height of oats [22], in Lactuca sativa, Curcumas sativus and Panicum miliaceum [23] and Triticum aestivum L. [24].

\section{Fresh and dry biomass}

The higher fresh shoot weight was found in T1 (V1,V2) after 7d treatment and was noted lowest in T4 (V1) with $0.207 \mathrm{~g}$ and T5 (V2) with $0.721 \mathrm{~g}$. The shoot fresh weight after $14 \mathrm{~d}$ treatment has been indicated in $\mathrm{T} 2$ (V1) and T3 (V2), while the lowest was indicated in T4 (V1) and T2 (V2).After 21d treatment the maximum shoot fresh weight has been indicated in T4(V1) and T3 (V2), whereas the lowest has been reported in $\mathrm{T} 4$ (V1) and T2 (V2) while After 7d treatment the highest shoot dry weight was found in T4(V1) and T2 (V2), while the lowest was noted in T3 (V1, V2). The upper limit shoot dry weight has been reported in T2 (V1) with $0.14 \mathrm{~g}$ and $\mathrm{T} 1$ (V2) with $0.145 \mathrm{~g}$ after $14 \mathrm{~d}$ treatment, whereas the smallest has been reported in T4 (V1) and T2 (V2). The higher dry weight of shoot was noted after 21d treatment in T4 (V1) and T3 (V2), while the lowest was noted in T3 (V1) and T4 (V2) (Table 2) while root maximum fresh weight has been reported after 7d, 14d, and 21d in T2 (V1), and in T3 (V2), whereas the lowest has been reported after in T3 (V1) and T5 (V2), T4 (V1) and T2(V2), and T1 (V1) and T2 (V2) respectively whereas dry weight has been found maximum $7 \mathrm{~d}$ and $14 \mathrm{~d}$ treatment in T2, T4 (V1) and T3 (V2), but the lowest has been noticed after 7d in T5 (V1, V2), after 14d in T4 (V1), T2 (V2) and after 21d treatment in T1 (V1) and T2 (V2) (Table 3). Similarly, benzoic acid at 100-400 mg L-1 increased seedling growth, biomass, flavonoid protein, carbohydrate and phenolic content of physiolas valgaris plant [25] and considerably increased totals insoluble and soluble carbohydrates in Ammi visnaga L. In previous studies it has also been reported that dry weight of root and their length of the Caesalpinia pulcherrima was repressed by $100 \mathrm{ppm}^{2+}$ [26], total root weight and root length of Triticum aestivum $\mathrm{L}$. was also affected by $20 \mathrm{mg} \mathrm{Pb}{ }^{2+}$ (VI) kg-1 [27]. 


\section{Leaf numbers, area, fresh and dry biomass}

Results of our study conform that $\mathrm{Pb}^{2+}$ stress is not only harmful for germination, shoot, root length and biomass but also harmful for leaf too. The maximum fresh leaf weight has been showed by T1 (V1, V2) after $7 \mathrm{~d}$ treatment with $0.093 \mathrm{~g}$ and $0.154 \mathrm{~g}$, while the lowest was found in T4 (V1) and T2 (V2). After 14d treatment the maximum leaf dry weight has been noted in T2 (V1) and T3 (V2) while the lowest has been reported in T4 (V1) and T2 (V2). After $21 \mathrm{~d}$ treatment the maximum leaf dry weight has been found in T5 (V1) and T3 (V2), whereas the minimum has been showed by T4 (V1, V2) respectively (Table 4). The maximum leaf dry weight has been noticed after 7d treatment in T1 (V1) and T2 (V2), whereas the minimum has been reported in T3 (V1) and T2 (V2). After 17d treatment the maximum leaf dry weight has been indicated in T2 (V1) and T3 (V2), while the minimum was reported in T3 (V1) an T2 (V2). The maximum leaf dry weight has been found after 21d treatment in T5 (V1) with $0.022 \mathrm{~g}$ and T3 (V2) with $0.038 \mathrm{~g}$, whereas the lowest has been reported in $\mathrm{T} 2$ (V1) and T4 (V2) (Table 4). No. of leaves has been found maximum in T1 (V1) and T3 (V2) after 7d treatment and the lowest has been noticed in T3 (V1) and T2 (V2). After $17 \mathrm{~d}$ treatment the maximum No. of leaves has been reported by T5 (V1) and $\mathrm{T} 4(\mathrm{~V} 2)$, while the minimum has been showed by T4 (V1) and T5 (V2). After 21d treatment the maximum No. of leaves has been indicated in T4(V1) and T5(V2) whereas the lowest has been reported in $\mathrm{T} 2$ (V1, V2) respectively (Table 4). Consequences of leaf area has been noticed maximum after $7 \mathrm{~d}$ treatment in $\mathrm{T} 2$ (V1) and T4 (V2), followed by T5 (V1) with $5.35 \mathrm{~cm}$ and T4 (V2) with $43.55 \mathrm{~cm}$, while the lowest was noticed in T4 (V1) and T5 (V2) respectively. After $14 \mathrm{~d}$ treatment the maximum leaf area has been reported in $\mathrm{T} 5$ (V1) and T3 (V2), while the lowest was indicated by T4 (V1) and T2 (V2). After 21d treatment the maximum leaf area has been showed by $\mathrm{T} 4$ (V1) $5.61 \mathrm{~cm}$ and $\mathrm{T} 3$ (V2) with $12.69 \mathrm{~cm}$, while the lowest has been found in T1 (V1) and T2 (V2) respectively (Table 5). Along with number of leaves in plant, heavy metals also affect the other aspects of leaves of different plants such as $\mathrm{Pb}^{2+}$ effect leaf biomass and area of Albizia lebbek [28], decrease in leaf area of primary and trifoliate leaves of bush bean plant [29], dry leaf yield of bush bean plants was also decreased [30], decrease in leaf dry weight and leaf area of Oryza sativa, Acacia holosericea, Leucaena leucocephala [31], and P. vulgaris [32], reduced leaf size of spinach [33], pretentious young leaves in tomato plants [34].

\section{Moisture contents, Field capacity, vigorous index}

Table 1 showed that maximum $\%$ moisture content has been reported in T5 (untreated control) in V1 (Jhanbaz) and T1 (2ppm $\mathrm{Pb}^{2+}$ ) in V2 (Galaxy 2013) after 7d treatment, followed by $\mathrm{T} 3\left(4 \mathrm{ppm} \mathrm{Pb}^{2+}\right)$, whereas the lowest has been reported in $\mathrm{T} 1$ $\left(2 \mathrm{ppm} \mathrm{Pb}^{2+}\right)$ in $\mathrm{V} 1$ with $0.033 \%$ and $\mathrm{T} 5$ (untreated control) in V2. The maximum \% moisture content after $14 \mathrm{~d}$ treatment was noted in $\mathrm{T} 1\left(2 \mathrm{ppm} \mathrm{Pb}^{2+}\right)$, followed by $\mathrm{T} 3$ $\left(4 \mathrm{ppm} \mathrm{Pb}^{2+}\right)$, while lowest was found in $\mathrm{T} 4$ (2ppm $\mathrm{Pb}^{2+}+\mathrm{HBA}$ ) in $\mathrm{V} 1$ and $\mathrm{T} 5$ (untreated control) in V2. After 21d treatment the maximum $\%$ moisture content was noted maximum in T5 (untreated control) in V1 with $5.925 \%$ and $\mathrm{T} 2\left(2 \mathrm{ppm} \mathrm{Pb}^{2+}+\mathrm{HBA}\right)$ in $\mathrm{V} 2$, followed by $\mathrm{T} 1\left(2 \mathrm{ppm} \mathrm{Pb}^{2+}\right)$ in $\mathrm{V} 1$ and $\mathrm{T} 4\left(2 \mathrm{ppm} \mathrm{Pb}^{2+}+\mathrm{HBA}\right)$ in $\mathrm{V} 2$, whereas the lowest has been reported in $\mathrm{T} 2\left(2 \mathrm{ppm} \mathrm{Pb}^{2+}\right.$ $+\mathrm{HBA})$ in $\mathrm{V} 1$ and $\mathrm{T} 1\left(2 \mathrm{ppm} \mathrm{Pb}^{2+}\right)$ in $\mathrm{V} 2$ respectively. The maximum F.C (field capacity) has been indicated in T3 (V1) and T1 (V2), followed by T1 (V1) and T3 (V2), while the lowest was found in T1 (V1) and T5 (V2) after 7d treatment. After 14 days' treatment the maximum F.C has been indicated in $\mathrm{T} 1$ (V1, V2) with 5.397$6.276 \%$, followed by $\mathrm{T} 3$, whereas the lowest was noted in T4 (V1) and T5 (V2). The maximum F.C has been reported after 21d treatment in T5 (V1) and T3 (V2), 
followed by T1 (V1) an T3 (V2), whereas the lowest was noted in T2 (V1) and T1 (V2). Maximum vigorous index has been reported in T3 (V1) and T5 (V2) after 7d treatment, while the minimum has been evaluated in $\mathrm{T} 2$ (V1, V2). After $17 \mathrm{~d}$ treatment the maximum vigorous index has been found in T1 (V1) with 768.6 and T5 (V2) with 929.90, while the lowest has been reported by $\mathrm{T} 4$. The maximum vigorous index has been noticed in T3 (V1) and T5 (V2), while the minimum has been showed by T2 (V1) and T4 (V2) respectively (Table 5). Similarly, result is also found by [35], the treatment $\mathrm{T} 2(2 \mathrm{ppm}+\mathrm{HBA})$ in both varieties showed the maximum values for the majority of agronomic characters among all the treatments. Treatment T2 (2ppm+HBA) showed the maximum vigor index in both varieties and was the best treatment of our research work. Maximum Vigor index was recorded in treatment T2 of Galaxy 2013 (2546.2 \pm 992.778), followed by treatment $\mathrm{T} 4$ of the same variety [36] whereas, treatment $\mathrm{T} 3(4 \mathrm{ppm})$ of both varieties was the worst treatment with the lowest vigor index in all samples.

\section{Rhizospheric soil and whole plant}

Table 6 exhibited the maximum concentration of lead in rhizospheric soil has been found maximum after $7 d$ treatment in T5 (V1) with 1.156 , followed by T4 (V2), while the lowest concentration has been found in T1 (V1,V2).After 14d treatment the maximum concentration after $14 \mathrm{~d}$ treatment has been recorded in $\mathrm{T} 3$ $(\mathrm{V} 1, \mathrm{~V} 2)$, whereas the lowest has been noticed in $\mathrm{T} 1$ (V1,V2).The maximum concentration of lead in rhizospheric soil has been showed after 21d treatment in T5 (V1) with 1.399 and T3 (V2) with 1.569, while the lowest has been reported in $\mathrm{T} 1$ (V1) and T5 (V2) respectively. The maximum concentration of lead in whole plant has been found maximum in T5 (V1) and T4 (V1) after 7d treatment, while the lowest has been noticed in T1 (V1) and T2 (V2). After $14 \mathrm{~d}$ treatment the maximum concentration has been found in T5 (V1) with 1.484 and T3 (V2) with 1.429, whereas the minimum concentration has been reported in T1 (V1) and T2 (V2) respectively. The maximum concentration of lead in whole plant after $21 \mathrm{~d}$ treatment has been found in T4 (V1) and T5 (V2), whereas the lowest has been reported in $\mathrm{T} 1$ (V1) and T4 (V2) respectively. Result is similar with the work of $[37,38]$ that showed Plants' responses to lead exposure are used as tools (biomarkers) in the context of environmental quality assessment. To develop tools for ecological study, understanding the mechanisms involved in plant absorption, transfer and toxicity is essential. 
Table 1. Influence of foliar spray of Hydroxyl benzoic acid on percent field capacity, soil moisture, and germination percentage of Triticum aestivum L. under inoculation of $\mathrm{Pb}^{2+}$ at $2 \mathrm{ppm}$ and $4 \mathrm{ppm}$

\begin{tabular}{|c|c|c|c|c|c|c|c|c|c|}
\hline \multirow{3}{*}{ Treatment } & \multicolumn{9}{|c|}{ Jhanbaz } \\
\hline & \multicolumn{3}{|c|}{$\%$ moisture } & \multicolumn{3}{|c|}{ Field capacity } & \multicolumn{3}{|c|}{ Germination } \\
\hline & $7 d$ & $14 d$ & 21d & $7 d$ & 14d & 21d & $7 d$ & 14d & 21d \\
\hline T1 & $0.03 \pm 0.00$ & $5.21 \pm 0.01$ & $5.23 \pm 1.17$ & $3.47 \pm 0.04$ & $5.40 \pm 0.10$ & $5.42 \pm 1.27$ & $11.00 \pm 1.41$ & $11.0 \pm 1.41$ & $1.39 \pm 0.03$ \\
\hline $\mathbf{T 2}$ & $0.04 \pm 0.02$ & $1.98 \pm 0.84$ & $2.65 \pm 1.44$ & $4.70 \pm 1.56$ & $2.00 \pm 0.87$ & $2.71 \pm 1.48$ & $12.50 \pm 1.41$ & $12.5 \pm 1.42$ & $5.62 \pm 1.84$ \\
\hline T3 & $0.05 \pm 0.01$ & $4.33 \pm 1.12$ & $4.40 \pm 0.61$ & $5.49 \pm 0.72$ & $4.47 \pm 1.19$ & $4.54 \pm 0.64$ & $15.00 \pm 2.12$ & $15.0 \pm 2.12$ & $3.31 \pm 0.64$ \\
\hline $\mathbf{T 4}$ & $0.04 \pm 0.00$ & $1.88 \pm 0.76$ & $4.66 \pm 1.23$ & $3.89 \pm 0.13$ & $1.90 \pm 0.79$ & $4.83 \pm 1.39$ & $13.50 \pm 2.12$ & $13.5 \pm 2.12$ & $5.31 \pm 1.19$ \\
\hline T5 & $0.05 \pm 0.01$ & $3.66 \pm 0.61$ & $5.93 \pm 3.63$ & $5.55 \pm 0.51$ & $3.76 \pm 0.64$ & $6.26 \pm 3.86$ & $12.50 \pm 1.41$ & $12.5 \pm 1.41$ & $2.62 \pm 0.87$ \\
\hline \multirow{3}{*}{ Treatment } & \multicolumn{9}{|c|}{ Galaxy 2013} \\
\hline & \multicolumn{3}{|c|}{$\%$ moisture } & \multicolumn{3}{|c|}{ Field capacity } & \multicolumn{3}{|c|}{ Germination } \\
\hline & 7d & 14d & 21d & $7 d$ & $14 d$ & 21d & 7d & 14d & 21d \\
\hline T1 & $0.13 \pm 0.05$ & $6.01 \pm 1.14$ & $1.38 \pm 0.35$ & $14.05 \pm 6.66$ & $6.27 \pm 1.25$ & $11.0 \pm 1.41$ & $12.5 \pm 2.828$ & $12.5 \pm 2.828$ & $12.5 \pm 2.828$ \\
\hline $\mathbf{T 2}$ & $0.07 \pm 0.00$ & $3.36 \pm 3.62$ & $5.39 \pm 1.72$ & $7.82 \pm 0.15$ & $3.53 \pm 3.86$ & $12.5 \pm 1.41$ & $12.5 \pm 1.414$ & $12.5 \pm 1.414$ & $12.5 \pm 1.414$ \\
\hline T3 & $0.09 \pm 0.05$ & $5.53 \pm 1.23$ & $3.23 \pm 0.06$ & $9.92 \pm 6.50$ & $5.75 \pm 1.31$ & $15.0 \pm 2.12$ & $12.5 \pm 1.414$ & $12.5 \pm 1.414$ & $12.5 \pm 1.414$ \\
\hline T4 & $0.07 \pm 0.02$ & $5.22 \pm 1.17$ & $5.12 \pm 1.12$ & $8.04 \pm 3.36$ & $5.42 \pm 1.26$ & $13.5 \pm 2.12$ & $16 \pm 0.707$ & $16 \pm 0.707$ & $16 \pm 0.707$ \\
\hline T5 & $0.05 \pm 0.00$ & $2.65 \pm 1.44$ & $2.57 \pm 0.84$ & $4.99 \pm 0.29$ & $2.71 \pm 1.48$ & $12.5 \pm 1.41$ & $11 \pm 1.414$ & $11.00 \pm 1.414$ & $11 \pm 1.414$ \\
\hline
\end{tabular}

T1 stands for $2 \mathrm{ppm}+\mathrm{Pb}^{2+}, \mathrm{T} 2=2 \mathrm{ppm} \mathrm{Pb}{ }^{2+}+\mathrm{HBA}, \mathrm{T} 3=4 \mathrm{ppm} \mathrm{Pb}^{2+}, \mathrm{T} 4=2 \mathrm{ppm} \mathrm{Pb}^{2+}+\mathrm{HBA}, \mathrm{T} 5=$ Untreated/control

Table 2. Effect of foliar spray of Hydroxyl benzoic acid on shoot length, fresh and dry biomass of Triticum aestivum L. under inoculation of $\mathrm{Pb}^{2+}$ at $2 \mathrm{ppm}$ and $4 \mathrm{ppm}$

\begin{tabular}{|c|c|c|c|c|c|c|c|c|c|}
\hline \multirow{3}{*}{ Treatment } & \multicolumn{9}{|c|}{ Jhanbaz } \\
\hline & \multicolumn{3}{|c|}{ Shoot length } & \multicolumn{3}{|c|}{ Shoot fresh weight } & \multicolumn{3}{|c|}{ Shoot dry weight } \\
\hline & 7d & 14d & 21d & 7d & 14d & 21d & 7d & $14 d$ & 21d \\
\hline T1 & $2.26 \pm 3.96$ & $26.0 \pm 0.35$ & $26.4 \pm 0.84$ & $0.56 \pm 0.14$ & $0.48 \pm 0.01$ & $0.34 \pm 0.011$ & $0.12 \pm 0.03$ & $0.13 \pm 0.01$ & $0.09 \pm 0.02$ \\
\hline $\mathbf{T 2}$ & $24.75 \pm 0.00$ & $28.35 \pm 0.21$ & $29.8 \pm 6.08$ & $0.456 \pm 0.09$ & $0.59 \pm 0.13$ & $0.34 \pm 0.05$ & $0.11 \pm 0.03$ & $0.14 \pm 0.04$ & $0.09 \pm 0.00$ \\
\hline T3 & $22.15 \pm 0.07$ & $24.1 \pm 4.38$ & $30.5 \pm 0.35$ & $0.22 \pm 0.00$ & $0.26 \pm 0.09$ & $0.267 \pm 0.022$ & $0.04 \pm 0.00$ & $0.05 \pm 0.01$ & $0.06 \pm 0.00$ \\
\hline $\mathbf{T 4}$ & $19.55 \pm 0.07$ & $18.65 \pm 0.91$ & $24.65 \pm 0.98$ & $0.20 \pm 0.01$ & $0.16 \pm 0.32$ & $0.36 \pm 0.021$ & $0.12 \pm 0.05$ & $0.04 \pm 0.00$ & $0.134 \pm 0.00$ \\
\hline T5 & $18.75 \pm 0.00$ & $28.6 \pm 5.16$ & $27.5 \pm 0.35$ & $0.34 \pm 0.13$ & $0.56 \pm 0.31$ & $0.32 \pm 0.09$ & $0.06 \pm 0.05$ & $0.14 \pm 0.07$ & $0.09 \pm 0.02$ \\
\hline \multicolumn{10}{|c|}{ Galaxy 2013} \\
\hline \multirow{2}{*}{ Treatment } & \multicolumn{3}{|c|}{ Shoot length } & \multicolumn{3}{|c|}{ Shoot fresh weight } & \multicolumn{3}{|c|}{ Shoot dry weight } \\
\hline & $7 d$ & 14d & 21d & $7 d$ & 14d & 21d & $7 d$ & 14d & 21d \\
\hline $\mathrm{T} 1$ & $9.85 \pm 2.05$ & $0.08 \pm 0.03$ & $43.45 \pm 7.99$ & $0.72 \pm 0.15$ & $0.76 \pm 0.51$ & $0.77 \pm 0.49$ & $0.08 \pm 0.03$ & $0.15 \pm 0.046$ & $0.20 \pm 0.10$ \\
\hline $\mathrm{T} 2$ & $7.7 \pm 0.77$ & $0.09 \pm 0.04$ & $24.85 \pm 10.53$ & $0.49 \pm 0.29$ & $0.24 \pm 0.20$ & $0.37 \pm 0.37$ & $0.09 \pm 0.04$ & $0.06 \pm 0.03$ & $0.09 \pm 0.08$ \\
\hline
\end{tabular}




\begin{tabular}{|c|c|c|c|c|c|c|c|c|c|}
\hline T3 & $8.7 \pm 1.90$ & $0.07 \pm 0.02$ & $42 \pm 11.68$ & $0.32 \pm 0.17$ & $0.97 \pm 0.47$ & $1.09 \pm 0.52$ & $0.07 \pm 0.02$ & $0.24 \pm 0.16$ & $0.26 \pm 0.10$ \\
\hline $\mathrm{T} 4$ & $7.05 \pm 1.27$ & $0.08 \pm 0.00$ & $37.00 \pm 0.35$ & $0.44 \pm 0.02$ & $0.54 \pm 0.00$ & $0.38 \pm 0.00$ & $0.08 \pm 0.00$ & $0.12 \pm 0.00$ & $0.09 \pm 0.00$ \\
\hline T5 & $6.05 \pm 0.28$ & $0.07 \pm 0.00$ & $39.25 \pm 4.95$ & $0.38 \pm 0.02$ & $0.40 \pm 0.03$ & $0.76 \pm 0.28$ & $0.07 \pm 0.00$ & $0.10 \pm 0.001$ & $0.19 \pm 0.07$ \\
\hline
\end{tabular}

T1 stands for 2ppm- $\mathrm{Pb}^{2+}, \mathrm{T} 2=2 \mathrm{ppm} \mathrm{Pb}{ }^{2+}+\mathrm{HBA}, \mathrm{T} 3=4 \mathrm{ppm} \mathrm{Pb}^{2+}, \mathrm{T} 4=2 \mathrm{ppm} \mathrm{Pb}^{2+}+\mathrm{HBA}, \mathrm{T} 5=$ Untreated/control

Table 3. Influence of foliar spray Hydroxyl benzoic acid on root length, dry and fresh biomass of triticum aestivum L. under inoculation of $\mathrm{Pb}^{2+}$ at $2 \mathrm{ppm}$ and $4 \mathrm{ppm}$

\begin{tabular}{|c|c|c|c|c|c|c|c|c|c|}
\hline \multirow{3}{*}{ Treatment } & \multicolumn{9}{|c|}{ Jhanbaz } \\
\hline & \multicolumn{3}{|c|}{ Root length } & \multicolumn{3}{|c|}{ Root fresh weight } & \multicolumn{3}{|c|}{ Root dry weight } \\
\hline & $7 d$ & 14d & 21d & $7 d$ & 14d & 21d & $7 d$ & 14d & 21d \\
\hline T1 & $11.25 \pm 0.21$ & $10.5 \pm 0.00$ & $12.00 \pm 2.13$ & $0.103 \pm 0.00$ & $0.13 \pm 0.06$ & $0.04 \pm 0.01$ & $0.06 \pm 0.00$ & $0.09 \pm 0.03$ & $0.04 \pm 0.01$ \\
\hline $\mathbf{T 2}$ & $10.88 \pm 4.56$ & $17.25 \pm 5.30$ & $13.75 \pm 1.41$ & $0.33 \pm 0.11$ & $0.28 \pm 0.15$ & $0.11 \pm 0.32$ & $0.21 \pm 0.10$ & $0.18 \pm 0.10$ & $0.08 \pm 0.02$ \\
\hline T3 & $10.3 \pm 0.49$ & $10.45 \pm 1.62$ & $14.50 \pm 1.41$ & $0.09 \pm 0.13$ & $0.12 \pm 0.02$ & $0.05 \pm 0.01$ & $0.06 \pm 0.01$ & $0.07 \pm 0.00$ & $0.04 \pm 0.01$ \\
\hline T4 & $10.8 \pm 4.66$ & $14.6 \pm 7.70$ & $14.00 \pm 1.41$ & $0.17 \pm 0.08$ & $0.09 \pm 0.01$ & $0.13 \pm 0.02$ & $0.05 \pm 0.02$ & $0.07 \pm 0.00$ & $0.12 \pm 0.02$ \\
\hline T5 & $08.35 \pm 1.20$ & $05.55 \pm 0.42$ & $12.4 \pm 0.56$ & $0.11 \pm 0.05$ & $0.12 \pm 0.02$ & $0.06 \pm 0.01$ & $0.03 \pm 0.02$ & $0.05 \pm 0.00$ & $0.04 \pm 0.01$ \\
\hline \multicolumn{10}{|c|}{ Galaxy 2013} \\
\hline \multirow[b]{2}{*}{ Treatment } & \multicolumn{3}{|c|}{ Root length } & \multicolumn{3}{|c|}{ Root fresh weight } & \multicolumn{3}{|c|}{ Root dry weight } \\
\hline & $7 d$ & $14 d$ & 21d & $7 d$ & $14 d$ & 21d & $7 d$ & $14 d$ & 21d \\
\hline T1 & $09.85 \pm 2.05$ & $07.50 \pm 1.06$ & $12.45 \pm 03.39$ & $0.093 \pm 0.03$ & $0.14 \pm 0.06$ & $0.06 \pm 0.01$ & $0.06 \pm 0.02$ & $0.06 \pm 0.00$ & $0.04 \pm 0.011$ \\
\hline $\mathrm{T} 2$ & $07.7 \pm 0.77$ & $09.40 \pm 0.56$ & $11.06 \pm 01.13$ & $0.07 \pm 0.038$ & $0.02 \pm 0.00$ & $0.05 \pm 0.00$ & $0.04 \pm 0.08$ & $0.07 \pm 0.00$ & $0.03 \pm 0.00$ \\
\hline T3 & $08.70 \pm 1.90$ & $5.85 \pm 1.06$ & $12.70 \pm 05.30$ & $0.11 \pm 0.091$ & $0.19 \pm 0.10$ & $0.11 \pm 0.07$ & $0.09 \pm 0.04$ & $0.09 \pm 0.07$ & $0.08 \pm 0.06$ \\
\hline T4 & $07.05 \pm 1.27$ & $11.05 \pm 0.35$ & $21.09 \pm 06.15$ & $0.08 \pm 0.01$ & $0.173 \pm 0.00$ & $0.07 \pm 0.02$ & $0.04 \pm 0.01$ & $0.09 \pm 0.00$ & $0.03 \pm 0.00$ \\
\hline T5 & $06.05 \pm 0.28$ & $07.85 \pm 1.34$ & $10.25 \pm 0.35$ & $0.03 \pm 0.00$ & $0.17 \pm 0.04$ & $0.05 \pm 0.00$ & $0.01 \pm 0.00$ & $0.06 \pm 0.07$ & $0.03 \pm 0.00$ \\
\hline
\end{tabular}

T1 stands for $2 \mathrm{ppm}-\mathrm{Pb}^{2+}, \mathrm{T} 2=2 \mathrm{ppm} \mathrm{Pb}{ }^{2+}+\mathrm{HBA}, \mathrm{T} 3=4 \mathrm{ppm} \mathrm{Pb}^{2+}, \mathrm{T} 4=2 \mathrm{ppm} \mathrm{Pb} \mathrm{Pb}^{2+}+\mathrm{HBA}, \mathrm{T} 5=$ Untreated/control

Table 4. Effect of foliar spray Hydroxyl benzoic acid on leaf numbers, leaf day and fresh biomass of Triticum aestivum L. under inoculation of $\mathrm{Pb}^{2+}$ at $2 \mathrm{ppm}$ and $4 \mathrm{ppm}$

\begin{tabular}{|c|c|c|c|c|c|c|c|c|c|}
\hline \multirow{3}{*}{ Treatment } & \multicolumn{9}{|c|}{ Jhanbaz } \\
\hline & \multicolumn{3}{|c|}{ Leaf fresh weight } & \multicolumn{3}{|c|}{ Leaf dry weight } & \multicolumn{3}{|c|}{ No of leaves } \\
\hline & 7d & 14d & 21d & 7d & 14d & 21d & $7 d$ & 14d & 21d \\
\hline $\mathrm{T} 1$ & $0.093 \pm 0.026$ & $0.0815 \pm 0.001$ & $0.052 \pm 0.011$ & $0.025 \pm 0.007$ & $0.0225 \pm 0.00$ & $0.0175 \pm 0.004$ & $11 \pm 0.707$ & $8.5 \pm 1.414$ & $10 \pm 1.414$ \\
\hline $\mathrm{T} 2$ & $0.091 \pm 0.008$ & $0.094 \pm 0.013$ & $0.057 \pm 0.012$ & $0.022 \pm 0.002$ & $0.024 \pm 0.004$ & $0.017 \pm 0.004$ & $8 \pm 0.707$ & $11.5 \pm 0.707$ & $8.5 \pm 0.707$ \\
\hline T3 & $0.057 \pm 0.00$ & $0.058 \pm 0.012$ & $0.061 \pm 0.004$ & $0.013 \pm 0.000$ & $0.02 \pm 0.0007$ & $0.019 \pm 0.0007$ & $6.5 \pm 0.707$ & $8.5 \pm 1.414$ & $8 \pm 0.707$ \\
\hline $\mathrm{T} 4$ & $0.037 \pm 0.007$ & $0.0375 \pm 0.004$ & $0.0495 \pm 0.006$ & $0.009 \pm 0.003$ & $0.016 \pm 0.0007$ & $0.019 \pm 0.0007$ & $7.5 \pm 0.00$ & $4.5 \pm 2.121$ & $10.5 \pm 0.00$ \\
\hline T5 & $0.079 \pm 0.023$ & $0.084 \pm 0.048$ & $0.071 \pm 0.020$ & $0.01 \pm 0.014$ & $0.02 \pm 0.014$ & $0.0225 \pm 0.002$ & $8 \pm 0.707$ & $12.00 \pm 2.121$ & $8.5 \pm 0.707$ \\
\hline \multicolumn{10}{|c|}{ Galaxy 2013} \\
\hline
\end{tabular}




\begin{tabular}{|c|c|c|c|c|c|c|c|c|c|}
\hline \multirow[b]{2}{*}{ Treatment } & \multicolumn{3}{|c|}{ Leaf fresh weight } & \multicolumn{3}{|c|}{ Leaf dry weight } & \multicolumn{3}{|c|}{ No of leaves } \\
\hline & $7 d$ & 14d & 21d & 7d & 14d & 21d & 7d & 14d & 21d \\
\hline $\mathrm{T} 1$ & $0.154 \pm 0.037$ & $0.1535 \pm 0.083$ & $0.122 \pm 0.011$ & $0.015 \pm 0.010$ & $0.044 \pm 0.015$ & $0.027 \pm 0.008$ & $7 \pm 1.414$ & $9.5 \pm 0.707$ & $11.5 \pm 3.535$ \\
\hline $\mathrm{T} 2$ & $0.091 \pm 0.053$ & $0.048 \pm 0.029$ & $0.067 \pm 0.048$ & $0.032 \pm 0.013$ & $0.0185 \pm 0.004$ & $0.023 \pm 0.011$ & $6.00 \pm 0.00$ & $8.00 \pm 0.707$ & $9.5 \pm 2.828$ \\
\hline T3 & $0.07 \pm 0.039$ & $0.162 \pm 0.076$ & $0.122 \pm 0.048$ & $0.021 \pm 0.006$ & $0.0525 \pm 0.016$ & $0.0385 \pm 0.013$ & $7.5 \pm 0.00$ & $9.5 \pm 1.414$ & $11 \pm 1.414$ \\
\hline $\mathrm{T} 4$ & $0.105 \pm 0.016$ & $0.104 \pm 0.009$ & $0.065 \pm 0.141$ & $0.021 \pm 0.005$ & $0.035 \pm 0.009$ & $0.0225 \pm 0.004$ & $7.5 \pm 0.00$ & $10.00 \pm 0.707$ & $9.5 \pm 0.707$ \\
\hline T5 & $0.107 \pm 0.007$ & $0.094 \pm 0.015$ & $0.084 \pm 0.006$ & $0.023 \pm 0.003$ & $0.0245 \pm 0.002$ & $0.024 \pm 0.002$ & $7.5 \pm 0.00$ & $9.00 \pm 0.00$ & $12 \pm 2.121$ \\
\hline
\end{tabular}

$\mathrm{T} 1$ stands for $2 \mathrm{ppm}-\mathrm{Pb}^{2+}, \mathrm{T} 2=2 \mathrm{ppm} \mathrm{Pb}{ }^{2+}+\mathrm{HBA}, \mathrm{T} 3=4 \mathrm{ppm} \mathrm{Pb}^{2+}, \mathrm{T} 4=2 \mathrm{ppm} \mathrm{Pb}^{2+}+\mathrm{HBA}, \mathrm{T} 5=$ Untreated/control

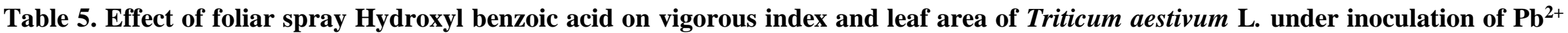
2ppm and 4ppm

\begin{tabular}{|c|c|c|c|c|c|c|c|c|c|c|c|c|}
\hline \multirow{3}{*}{ Treatment } & \multicolumn{6}{|c|}{ Jhanbaz } & \multicolumn{6}{|c|}{ Galaxy 2013} \\
\hline & \multicolumn{3}{|c|}{ Leaf area } & \multicolumn{3}{|c|}{ Vigorous index } & \multicolumn{3}{|c|}{ Leaf area } & \multicolumn{3}{|c|}{ Vigorous index } \\
\hline & $7 d$ & $14 d$ & 21d & $7 d$ & $14 d$ & 21d & $7 d$ & $14 d$ & 21d & $7 d$ & $14 d$ & 21d \\
\hline T1 & $5.72 \pm 1.89$ & $7.32 \pm 0.035$ & $4.47 \pm 0.99$ & $645.57 \pm 5.39$ & $1025.48 \pm 6.87$ & $645.57 \pm 5.39$ & $10.48 \pm 2.77$ & $13.95 \pm 3.28$ & $9.783 \pm 2.81$ & $639.99 \pm 5.60$ & $900.11 \pm 7.04$ & $1053.0 \pm 5.66$ \\
\hline T2 & $6.08 \pm 0.05$ & $8.08 \pm 1.30$ & $6.12 \pm 1.61$ & $509.76 \pm 7.29$ & $1501.69 \pm 8.01$ & $509.76 \pm 7.29$ & $8.58 \pm 4.41$ & $4.71 \pm 1.88$ & $5.85 \pm 3.81$ & $403.2 \pm 0.98$ & $802.64 \pm 2.74$ & $982.56 \pm 2.80$ \\
\hline T3 & $5.35 \pm 0.91$ & $5.7 \pm 0.84$ & $6.77 \pm 0.77$ & $768.6 \pm 8.89$ & $2072.7 \pm 7.32$ & $768.6 \pm 8.89$ & $43.55 \pm 55.64$ & $18.66 \pm 8.73$ & $12.69 \pm 4.62$ & $885.51 \pm 4.36$ & $1033.2 \pm 4.95$ & $995.89 \pm 5.66$ \\
\hline T4 & $4.13 \pm 0.43$ & $4.2 \pm 0.67$ & $5.61 \pm 0.38$ & $526.68 \pm 8.26$ & $882 \pm 10.35$ & $526.68 \pm 8.26$ & $67.64 \pm 42.22$ & $10.52 \pm 2.30$ & $8.005 \pm 2.00$ & $591.5 \pm 6.01$ & $696.8 \pm 6.02$ & $951.00 \pm 4.68$ \\
\hline T5 & $6.02 \pm 1.47$ & $8.29 \pm 3.16$ & $5.25 \pm 0.05$ & $721.59 \pm 7.72$ & $1055.68 \pm 9.86$ & $721.59 \pm 7.72$ & $7.53 \pm 0.91$ & $10.01 \pm 0.79$ & $9.26 \pm 1.03$ & $929.90 \pm 5.40$ & $1273.38 \pm 8.48$ & $1682.36 \pm 5.49$ \\
\hline
\end{tabular}

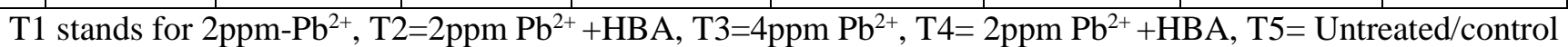

Table 6. Influence of foliar spray Hydroxyl benzoic acid on rhizospheric soil and whole plant of Triticum aestivum L. under inoculation of $\mathrm{Pb}^{2+} 2$ ppm and 4 ppm

\begin{tabular}{|c|c|c|c|c|c|c|c|c|c|c|c|c|}
\hline \multirow{3}{*}{ Treatment } & \multicolumn{6}{|c|}{ Jhanbaz } & \multicolumn{6}{|c|}{ Galaxy 2013} \\
\hline & \multicolumn{3}{|c|}{ Rhizospheric soil } & \multicolumn{3}{|c|}{ Whole plant } & \multicolumn{3}{|c|}{ Rhizospheric soil } & \multicolumn{3}{|c|}{ Whole plant } \\
\hline & $7 d$ & 14d & 21d & $7 d$ & 14d & 21d & $7 d$ & 14d & 21d & $7 d$ & 14d & 21d \\
\hline T1 & $0.72 \pm 0.01$ & $1.36 \pm 0.03$ & $1.17 \pm 0.01$ & $1.16 \pm 0.02$ & $1.31 \pm 0.03$ & $1.26 \pm 0.06$ & $1.00 \pm 0.01$ & $1.29 \pm 0.02$ & $1.42 \pm 0.01$ & $1.29 \pm 0.04$ & $1.40 \pm 0.07$ & $1053.0 \pm 5.663$ \\
\hline T3 & $1.04 \pm 0.04$ & $1.38 \pm 0.01$ & $1.30 \pm 0.02$ & $1.24 \pm 0.05$ & $1.4 \pm 0.06$ & $1.37 \pm 0.07$ & $1.05 \pm 0.01$ & $1.54 \pm 0.05$ & $1.56 \pm 0.07$ & $1.31 \pm 0.02$ & $1.42 \pm 0.09$ & $995.89 \pm 5.661$ \\
\hline T4 & $1.07 \pm 0.03$ & $1.26 \pm 0.05$ & $1.35 \pm 0.07$ & $1.28 \pm 0.03$ & $1.37 \pm 0.03$ & $1.55 \pm 0.08$ & $1.13 \pm 0.07$ & $1.37 \pm 0.12$ & $1.52 \pm 0.02$ & $1.35 \pm 0.06$ & $1.34 \pm 0.15$ & $951.00 \pm 4.683$ \\
\hline T5 & $1.15 \pm 0.05$ & $1.31 \pm 0.02$ & $1.39 \pm 0.03$ & $1.39 \pm 0.04$ & $1.48 \pm 0.04$ & $1.42 \pm 0.09$ & $1.31 \pm 0.05$ & $1.32 \pm 0.03$ & $1.38 \pm 0.01$ & $1.30 \pm 0.01$ & $1.36 \pm 0.07$ & $1682.36 \pm 5.490$ \\
\hline
\end{tabular}

$\mathrm{T} 1$ stands for $2 \mathrm{ppm}_{-} \mathrm{Pb}^{2+}, \mathrm{T} 2=2 \mathrm{ppm} \mathrm{Pb}{ }^{2+}+\mathrm{HBA}, \mathrm{T} 3=4 \mathrm{ppm} \mathrm{Pb}^{2+}, \mathrm{T} 4=2 \mathrm{ppm} \mathrm{Pb}{ }^{2+}+\mathrm{HBA}, \mathrm{T} 5=$ Untreated/control 


\section{Conclusion}

The effect of heavy metal (lead) research can be applied to so many current wheat problems including adverse effect on crop productivity. Keeping in views of these problems the present study was aimed to evaluate the effect of heavy metal (lead) on Triticum aestivum $\mathrm{L}$. in response to hydro benzoic acid foliar spray. Results postulated that this lead had adverse effect on Triticum aestivum L. seedling agronomic characters. The effect of heavy metal (lead) resulted reduction in growth parameters in wheat has been improved by exogenous foliar application of hydro benzoic acid (HBA) thus illustrated that hydro benzoic acid plays a positive role in enhancing plant growth under heavy metal stress.

\section{Authors' contributions}

Conceived and designed the experiments: $\mathrm{N}$ Dilawar, \& F Asad, Performed the experiments: N Dilawar \& Samiullah, Analyzed the data: N Dilawar \& F Asad, Contributed materials/ analysis/ tools: N Dilawar Wisal \& S Shahid. Wrote the paper: N Dilawar \& F Asad.

\section{References}

1. Alexander PD, Alloway BJ \& Dourado AM (2006). Genotypic variations in the accumulation of $\mathrm{Cd}, \mathrm{Cu}, \mathrm{Pb}$ and $\mathrm{Zn}$ exhibited by six commonly grown vegetables. Environ Pollut 144: 736-745.

2. Adriano DC (2001). Trace Elements in Terrestrial Environments; Biochemistry, Bioavailability and Risks of Metals. Springer-Verlag, New York, pp150-159.

3. Cheng C, Phipps D \& Alkhaddar RM (2005). Treatment of spent metalworking fluids. Wat Res 39(17): 4051-4063.

4. Capuana M (2011). Heavy metals and woody plants-biotechnologies for phytoremediation. J. Biogeo Sci For 4: 715.

5. Gao X, Flaten DF, Tenuta M, Grimmett MG, Gawalko EJ \& Grant CA (2011). Soil solution dynamics and plant uptake of cadmium and zinc by durum wheat following phosphate fertilization. Pla soi, 338(1-2): 423-434.

6. Gupta D, Nicoloso F, Schetinger M, Rossato L, Pereira L, Castro G, Srivastava
S \& Tripathi R (2009) Antioxidant defense mechanism in hydroponically grown Zea mays seedlings under moderate lead stress. J Hazard Mater 172(1): 479-484.

7. Johansson L \& Pellicciari CE (1988). Lead induced changes in the stabilization of the mouse sperm chromatin. Toxicology 51: $11-24$

8. Kosobrukhov A, Knyazeva I \& Mudrik V (2004). Plantago major plants responses to increase content of lead in soil: growth and photosynthesis. Pla Gro Reg 42: 145-151.

9. Lukaszek M \& Taj P (1998). Development of photosynthetic apparatus and respiration in pea seedlings during greening as influenced by toxic concentration of lead. Acta Phy Plant 20: 35.

10. Lynch JM \& Whipps JM (1990). Substrate flow in the rhizosphere. Pla Soi 129: 1-10.

11. Lamhamdi M, Bakrim A, Aarab A, Lafont R, Sayah F (2011). Effects of lead phytotoxicity on wheat (Triticum aestivum L.) seed germination and seedling growth. Compt Rend biol 334, 118-126.

12. Macpherson AN, Arellana JB, Fraser NJ, Cogdell RJ \& Gilboro T (2001) Biophy J 80: 923-930.

13. Maestri E, Marmiroli M, Visioli G \& Marmiroli N (2010). Metal tolerance and hyperaccumulation: costs and trade-offs between traits and environment. Envi Exp Bot 68(1): 1-13.

14. Robinson, Mills BH, Petit TM, Fung DLE, Green SR \& Clothier BE (2000). Natural and induced cadmium-accumulation in poplar and willow: Implications for phytoremediatiion. Pla soi 227(1-2): 301387.

15. Sharma, P. and R.S. Dubey. 2005. Lead toxicity in plants. Braz J Plant Physiol., 17(1):35-52.

16. Shyama R, Weerakoon \& Somaratne $S$ (2009). Phytoextractive potential among mustard (Brassica juncea) genotypes in Serilanca. Biol Sci 38(2): 85-93.

17. Traunfeld JH \& Clement DL (2001). Lead in Garden Soils. Home and Garden.College Park, MD: Maryland Cooperative Extension, University of Maryland.

18. Asad F, Begum HA, Hamayun M, Hameed R, Yaseen T \& Khan A (2018). Efficacy of different solvent extracts from selected medicinal plants for the potential of 
antibacterial activity. Pure Appl Biol 7(2): 890-896.

19. Dey SK, Jena PP \& Kundu S (2009). Antioxidative efficiency of Triticum aestivum L. exposed to chromium stress. $J$ Envi Biol 30: 539-544.

20. Peralta JR, Gardea-Torresdey JL, Tiemann KJ, Gomez E \& Arteaga S (2001). Uptake and effects of five heavy metals on seed germination and plant growth in alfalfa (Medicago sativa L.). Bull Environ Contam Toxicol 66: 727-734.

21. Mathur S, Kalaji HM \& Jajoo A (2016). Investigation of deleterious effects of chromium phytotoxicity and photosynthesis in wheat plant. Photosynthetica 54: 185-192.

22. Del Real AP, Gonzalo PG, Rodríguez AG, Lobo MC \& Sanz AP (2013). Effect of genotype, Cr (III) and Cr (VI) on plant growth and micronutrient status in Silene vulgaris (Moench). Span J Agri Res 11: 685-694.

23. Diwan H, Ahmad A \& Iqbal M (2012). Characterization of Chromium Toxicity in Food Crops and their Role in Phytoremediation. J Bior Biod 3: 159.

24. Sharma DC \& Mehrotra SC (1993). Chromium accumulation and its effects on wheat (Triticum aestivum L. cv. HD 2204) metabolism. Pla Sci 111: 145-151.

25. Sadak MSH, SR El-Lethy \& MG Dawood (2013). Physiological role of benzoic acid and salicylic acid on growth, yield, some biochemical and antioxidant aspects of soybean plant. Worl J Agric Sci 9 (6): 435442.

26. Barcelo J, Poschenrieder C \& Gunse B (1986) Water relations of chromium VI treated bush bean plants (Phaseolus vulgaris L cv Contender) under both normal and water stress conditions. $J$ Exp Bot 37: 178-187.

27. Chen NC, Kanazawa S, Horiguchi $\mathrm{T}$ \& Chen NC (2001). Effect of chromium on some enzyme activities in the wheat rhizosphere. Soil Micro 55: 3-10.

28. Barcelo J, Poschenriender C, Ruano A \& Gunse B (1985). Leaf water potential in $\mathrm{Cr}$
(VI) treated bean plants (Phaseolus vulgaris L). Pla Phy Supp 77: 163-164.

29. Wallace, Soufi SM, Cha JW \& Romney EM (1976). Some effects of chromium toxicity on bush bean plants grown in soil. Pla Soi 44: 471-473.

30. Karunyal S, Renuga G \& Kailash P (1994). Effects of tannery effluent on seed germination, leaf area, biomass and mineral content of some plants. Bior Tech 47: 215-218.

31. Poschenrieder C, Gunse B \& Barcelo J (1993). Chromium-induced inhibition of ethylene evolution in bean (Phaseolus vulgaris) leaves. Phys Plant 89: 404-408.

32. Singh AK (2001). Effect of trivalent and hexavalent chromium on spinach (Spinacea oleracea L). Envi Ecol 19: 807810.

33. Pedreno NJI, Gomez R, Moral G, Palacios J \& Mataix J (1997). Heavy metals and plant nutrition and development. Rec Res Dev Phytoc 1: 173-179.

34. Kazmi A, Usman M \& Muhammad W (2019). Effect of Hydroxybenzoic Acid Foliar Spray on Selected Wheat Varieties under Induced Heavy Metal Stress. Glob J Res Rev 6: 1-8.

35. Naeem MI, Bhatti I, Ahmad RH \& Ashraf MY (2004). Effect of some growth harmones (GA3, IAA and kinetin) on the morphology and early or delayed initiation of bud of lentil (Lens culinaris Medik). Pak J Bot 36: 801-809.

36. Islam MK, Khanam S, Lee SY, Alam I \& Huhl MR (2014). The interaction of arsenic (As) and chromium (Cr) influences growth and antioxidant status in tossa jute (Corchorus olitorius). Pla Omics 7: 499.

37. Wierzbicka MH, Przedpeska E, Ruzik R, Ouerdane L, Poec'-PawlakK, Jarosz M, Szpunar J \& Szakiel A (2007). Comparison of the toxicity and distribution of cadmium and lead in plant cells. Protoplasma 231, 99-111.

38. Begum HA, Asad F, Sadiq A, Mulk S \& Ali K (2019). Antioxidant, antimicrobial activity and phytochemical analysis of the seeds extract of Cucumis sativus Linn. Pure and Appl Biol 8(1): 433-441. 